\title{
Classification of caesarean section based on Robson ten group classification system in our hospital
}

\author{
Ari Sharma $^{1 *}$, Dipika Singh ${ }^{1}$, Sarika Verma1 ${ }^{1}$, Sanjog Sharma $^{2}$
}

\author{
${ }^{1}$ Department of Obstetrics and Gynaecology, Employee State Insurance Hospital, Okhla, New Delhi \\ ${ }^{2}$ Department of Plastic Surgery, Maulana Azad Medical College and associated Lok Nayak Hospital, New Delhi
}

Received: 06 August 2020

Revised: 12 September 2020

Accepted: 15 September 2020

\author{
*Correspondence: \\ Dr. Arti Sharma, \\ E-mail: sdrarti01@gmail.com
}

Copyright: (c) the author(s), publisher and licensee Medip Academy. This is an open-access article distributed under the terms of the Creative Commons Attribution Non-Commercial License, which permits unrestricted non-commercial use, distribution, and reproduction in any medium, provided the original work is properly cited.

\begin{abstract}
Background: Recent data indicate that one in five women undergo caesarean section (CS). In the last decade, there has been a dramatic increase in the caesarean section rate worldwide, which now exceeds $30 \%$ in some regions. Thus, the increasing rate of caesarean section became a matter of international public health concern. Our study aimed to classify the CS-based on Robson ten group classification system (RTGCS) criteria which will subsequently enable us to standardise the indication of CS and establish protocols to reduce the number of CS in our set up.

Method: A retrospective study was conducted in ESI Hospital, New Delhi wherein Robson TGCS was used to classify CS for 15 months (January 2019 to April 2020).

Results: Overall CS rate in our hospital over the specified period was $34.5 \%$. All women with one or more previous cesareans (group V) had the maximum number of cesareans, $37 \%$, followed by nulliparous, single, cephalic, term pregnancy (induced) i.e group II, $22.1 \%$ and nulliparous women more than 37 weeks in spontaneous labour (group I), $9.5 \%$.

Conclusions: RTGCS is easy to comprehend and reproduce. All deliveries and cesareans should be universally categorized by the Robsons TGCS. An attempt should be made to evaluate the group contributing most to the CS rate and interventions should be made accordingly.
\end{abstract}

Keywords: Caesarean section, Robson ten group classification system, pregnancy

\section{INTRODUCTION}

Recent data indicate that one in five women undergo caesarean section (CS), and in most regions of the world, CS rates continue to rise. ${ }^{1}$ In the last decade, there has been a dramatic increase in the Caesarean section rate worldwide, which now exceeds $30 \%$ in some regions. ${ }^{2}$ Worries over such increases have led the world health organization to advise that caesarean section rates should not be more than $15 \%$ as an increase in CS rate is not associated with an additional reduction in maternal and neonatal mortality and morbidity. ${ }^{3,4}$ Thus, the increasing rate of caesarean section became a matter of international public health concern. ${ }^{5}$

World health organization (WHO) has recommended classifying all CS in a standard, reliable grouping system. Of the many proposed classification system WHO and the international federation of gynecology and obstetrics (FIGO) have identified robson ten group classification system (TGCS) to be the most appropriate classification system to be used globally for monitoring, comparing and understanding caesarean rates over time and between different institutions. ${ }^{6-9}$ 
Our study aimed to classify the CS-based on RTGCS criteria and address the factors contributing to increasing CS cases in our scenario which will subsequently enable us to standardise the indication of $\mathrm{CS}$ and establish protocols to reduce the number of CS in our set up.

\section{METHODS}

This was a retrospective study carried in our hospital from January 2019 to April 2020 in the department of Obstetrics and Gynaecology, ESI Hospital, Okhla, New Delhi. Data was compiled based on robson-10 group classification system in a preformed structured pro forma (Table 1).

Table 1: Robson ten group classification system (TGCS).

\begin{tabular}{|c|c|}
\hline $\begin{array}{l}\text { Robson } \\
\text { group }\end{array}$ & Characteristics \\
\hline I & $\begin{array}{l}\text { Nulliparous; single cephalic term pregnancy; } \\
\text { spontaneous labour }\end{array}$ \\
\hline IIA & $\begin{array}{l}\text { Nulliparous; single cephalic term pregnancy; } \\
\text { induced labour }\end{array}$ \\
\hline IIB & $\begin{array}{l}\text { Nulliparous; single cephalic term pregnancy; } \\
\text { planned caesarean delivery }\end{array}$ \\
\hline III & $\begin{array}{l}\text { Multiparous without uterine scar; single } \\
\text { cephalic term pregnancy; spontaneous labour }\end{array}$ \\
\hline IVA & $\begin{array}{l}\text { Multiparous without uterine scar; single } \\
\text { cephalic term pregnancy; induced labour }\end{array}$ \\
\hline IVB & $\begin{array}{l}\text { Multiparous without uterine scar; single } \\
\text { cephalic term pregnancy; planned caesarean } \\
\text { delivery }\end{array}$ \\
\hline $\mathbf{V}$ & $\begin{array}{l}\text { Multiparous with previous caesarean section; } \\
\text { single cephalic term pregnancy }\end{array}$ \\
\hline VI & Nulliparous; single breech pregnancy \\
\hline VII & Multiparous; single breech pregnancy \\
\hline VIII & All women with multiple pregnancy \\
\hline IX & $\begin{array}{l}\text { All women with a single oblique or } \\
\text { transverse pregnancy }\end{array}$ \\
\hline $\mathbf{X}$ & $\begin{array}{l}\text { All women with a single cephalic preterm } \\
\text { pregnancy }\end{array}$ \\
\hline
\end{tabular}

The parameters considered were according to the classification system: Parity (with/without previous CS), Gestational age (>37 weeks/<37 weeks), Fetal presentation (cephalic/breech/abnormal lie), Number of fetuses (single/multiple), Onset of labour (spontaneous/ induced/preterm).

For each case, data was collected from the delivery register maintained in our labour room. Details were entered in the Microsoft Excel sheet and analysed. Total of 1013 records was analysed out of which 16 were excluded from the group as they had incomplete information regarding the indication of $\mathrm{CS}$ and/or period of gestation. Thus, a total of 997 cases were included in our study.

\section{RESULTS}

The total number of deliveries over this period in the hospital was 2936 out of which the number of cesarean section was 1013 which denotes that overall CS rate in our hospital over the specified period was $34.5 \%$. Total of 1013 records was analysed out of which 16 were excluded from the group as they had incomplete information regarding the indication of CS and/or period of gestation. Thus, a total of 997 cases were included in our study.

On analysis of CS according to Robson's classification, different rate of each group was shown separately (Table 2).

Table 2: Distribution of CS based on Robson criteria $(\mathbf{n}=997)$.

\begin{tabular}{|lll|}
\hline Class & $\mathbf{N}$ & Percentage \\
\hline I & 95 & 9.5 \\
\hline IIA & 221 & 22.1 \\
\hline IIB & 37 & 3.7 \\
\hline III & 71 & 7.12 \\
\hline IVA & 48 & 4.8 \\
\hline IVB & 19 & 1.9 \\
\hline V & 369 & 37 \\
\hline VI & 44 & 4.4 \\
\hline VII & 35 & 3.5 \\
\hline VIII & 17 & 1.7 \\
\hline IX & 10 & 1 \\
\hline $\mathbf{X}$ & 31 & 3.1 \\
\hline
\end{tabular}

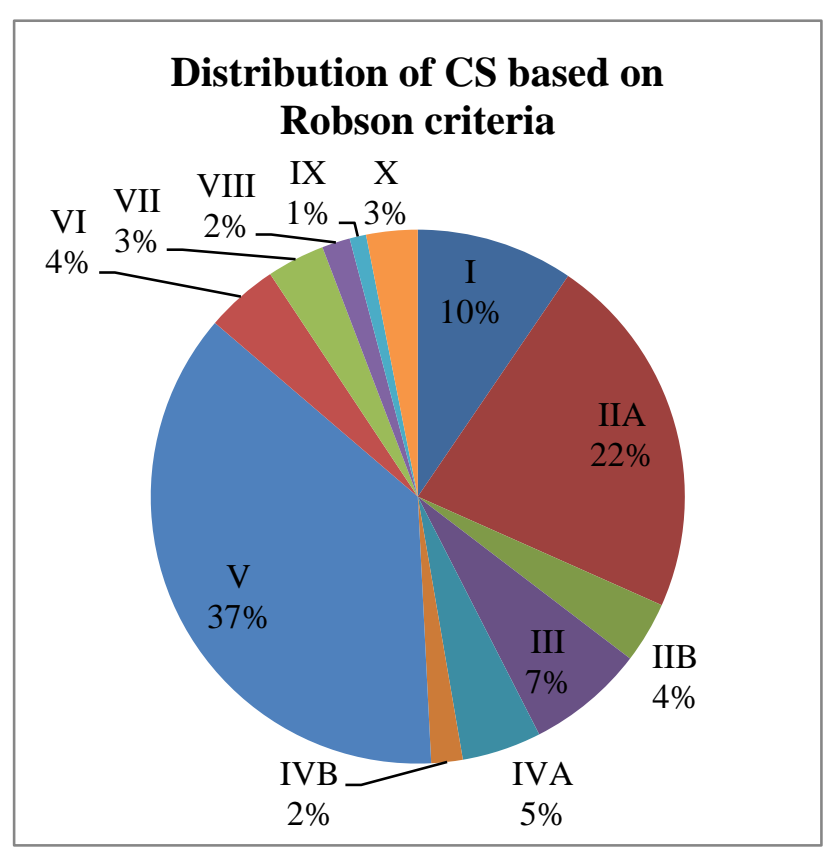

Figure 1: Distribution of CS based on Robson criteria. 
All women with one or more previous caesareans (group V) had the maximum number of caesareans, 37\%, followed by nulliparous, single, cephalic, term pregnancy (induced) i.e group II, $22.1 \%$ and nulliparous women more than 37 weeks in spontaneous labour (group I), $9.5 \%$.

Group V was further analysed for the indication of CS and it was found that out of 369 cases 146 cases were elective $(39.5 \%)$ and 223 cases were emergency caesarean cases $(60.4 \%)$ (Figure 1).

Out of 223 cases, 73 cases were due to failed trial of labour after caesarean (TOLAC) i.e $32.7 \%$ cases.

\section{DISCUSSION}

For the last 30 years, there has been public concern about increasing caesarean rate. ${ }^{10}$ Thus, our study was an attempt to standardise and classify the CS for the first time in our department based on Robson criteria. It helped us to analyse which clinical group contributed most to the CS.

In our present study, we observed that the total number of CS in our hospital over 15 months was $34.5 \%$ which was quite high compared to WHO cut off of $15 \% .^{3}$

In India, the CS rate has increased from $16.4 \%$ (2014) to $18 \%(2015-16)$ as per the national family health survey. Average CS rate in Asian countries is $27.3 \%$ which is much lower compared to USA $(31 \%) .{ }^{11-12}$

Based on our study, Group V contributed the most to the overall CS rate $(37 \%)$. This was similar to the study conducted by Vogel et al who concluded that the proportion of women with previous CS has increased along with CS rate in these women. ${ }^{13}$ A similar study was conducted in Brazil with a similar outcome that is Group $\mathrm{V}$ contributed to $31.3 \%$ of the total CS rate. ${ }^{14}$

Other groups that significantly contributed to the increased CS rate in our study was Group I and IIA accounting for $9.5 \%$ and $22.1 \%$ respectively. A similar study was conducted in Peru from 2000 to 2010 and it was observed that group I and III along with Group V and VII were the major contributor to the increasing rate of CS. ${ }^{15}$

There was another study conducted in Spain in the year 2010 and result was similar to our study with Group I $(20.4 \%)$ and Group II $(29.4 \%)$ as a second major contributor to increasing CS rate after group V. ${ }^{16}$

Based on our study and the results of other studies across the world we believe 3 major concerns need to be addressed to limit the increasing CS rate. The first and the most critical is that every hospital should adopt clear guideline regarding induction of labour. Induction of labour should be limited for a specific indication as induction, especially in unfavourable cervix with no other indication, can significantly add up to increase the rate of CS. Also, we need to revise our guideline for induction of labour in post-dated pregnancy and adhere to a policy of induction only after 41 completed weeks.

The second concern is regarding two common indications of CS i.e failure to progress and non-reassuring fetal heart rate. Some recent studies on singleton cephalic, term pregnancy in spontaneous labour concluded that active labour (cervical dilation $1-1.5 \mathrm{~cm} /$ hour) only begins after $6 \mathrm{~cm}$ dilation and some women may take longer to reach active phase $(6 \mathrm{~cm})$. Thus, without a proper guideline, some woman will undergo CS even before reaching the active phase of labour.

The increased use of nonstress test (NST) for fetal heart monitoring has done more harm than benefit. Some randomized controlled trial (RCT) has established that it has a false-positive value of $99.8 \%$ and is associated with a high rate of $\mathrm{CS} .{ }^{17}$

Thus, each hospital should establish their guideline regarding the use of NST and obstetrician should have a thorough knowledge regarding the interpretation of NST.

The third important issue that needs to be highlighted is incorporating VBAC in our day to day practice and every institution should strictly adhere to the protocols of TOLAC as an increase in CS rate has been associated with an increase in maternal mortality. 18 Thus every attempt should be made to limit the CS even in women with previous CS. It has been found that the number of women opting for VBAC has declined over recent years due to fear of uterine rupture. ${ }^{19}$ Thus proper patient counselling and addressing all their queries regarding VBAC should be dealt diligently.

\section{CONCLUSION}

Every attempt should be made to decrease the CS rate to decrease maternal mortality across the world. All deliveries and caesareans should be universally categorized by the Robson TGCS. An attempt should be made to evaluate the group contributing most to the CS rate and interventions should be made accordingly. Patient counselling should be done in detail especially in the case of previous CS. Institution protocols should be strictly followed with time to time audit to rationalise the CS rates.

\section{Funding: No funding sources \\ Conflict of interest: None declared \\ Ethical approval: The study was approved by the Institutional Ethics Committee}

\section{REFERENCES}

1. Betran AP, Ye J, Moller AB, Zhang J, Gulmezoglu $\mathrm{AM}$, Torloni MR. The Increasing trend in caesarean 
section rates: global, regional and national estimates: 1990-2014. PLo. ONE 2016;11:e0148343.

2. National Institutes of Health state-of-the-science conference statement. Cesarean delivery on maternal request. Obstet Gynecol. 2006;107:1386-97.

3. World Health Organization. Monitoring emergency obstetric care: a handbook. Geneva, Switzerland; 2009.

4. Althabe F, Belizán JM. Caesarean section: the paradox. (comment). Lanc. 2006;368(9546):1472-3

5. Marshall NE, Fu R, Guise JM. Impact of multiple cesarean deliveries on maternal morbidity: a systematic review. Am J Obstet Gynecol. 2011;205(3):262-8.

6. Robson MS. Can we reduce the cesarean section rate? Best Pract Res Clin Obstet Gynaecol. 2001;15:179-94.

7. Torloni MR, Betran AP, Souza JP, Widmer M, Allen $\mathrm{T}$, et al. Classifications for cesarean section: a systematic review. PLo One. 2011;6:14566-7.

8. Best practice advice on the 10-Group Classification System for cesarean deliveries. FIGO Working Group on Challenges in Care of Mothers and Infants during Labour and Delivery. 2016;135:232-3

9. Betran AP, Vindevoghel N, Souza JP, Gulmezoglu AM, Torloni MR. A systematic review of the Robson Classification for caesarean section: what works, doesn't work and how to improve it. PLo On. 2014;9:97769.

10. Robson M. Classification of caesarean sections. Fetal Matern Med Rev. 2001;12:23-39.

11. Lumbiganon P, Laopaiboon M, Gulmezoglu AM, Souza JP, Taneepanichskul S, Ruyan P, et al. Method of delivery and pregnancy outcomes in Asia: the WHO global survey on maternal and perinatal health 2007-08. Lancet. 2010;375(9713):490-9.

12. MacDorman MF, Menacker F, Declercq E. Cesarean birth in the United States: epidemiology, trends, and outcomes. Clin Perinatol. 2008;35(2):293-307.
13. Vogel JP, Betrán AP, Vindevoghel N, Souza JP, Torloni MR, Zhang J, et al., Use of the Robson classification to assess caesarean section trends in 21 countries: a secondary analysis of two WHO multicountry surveys. Lanc Glob Heal. 2015;3(5):260-70.

14. Rudey EL, Leal MDC, Rego G. Cesarean section rates in Brazil: Trend analysis using the Robson classification system. Medici. 2020;99(17):19880.

15. Tapia V, Betran AP, Gonzales GF. Caesarean Section in Peru: Analysis of Trends Using the Robson Classification System. PLo On. 2016; 11(2):e0148138.

16. Vila-Candel R, Martín A, Escuriet R, CastroSánchez E, Soriano-Vidal FJ. Analysis of Caesarean Section Rates Using the Robson Classification System at a University Hospital in Spain. Int $\mathbf{J}$ Environ Res Pub Heal. 2020;17(5):1575.

17. Nelson K, Sartwelle T, Rouse D. Electronic fetal monitoring, cerebral palsy, and caesareans: assumptions versus evidence. Brits Med J. 2016;355:16405.

18. Souza JP, Betran AP, Dumont A, De Mucio B, Gibbs Pickens CM, Deneux-Tharaux C, et al. A global reference for caesarean section rates (C-Model): a multicountry cross-sectional study. Int $\mathrm{J}$ Obstetr Gynaecol. 2016;123(3):427-36.

19. Al-Zirqi I, Stray-Pedersen B, Forsen L, Vangen S. Uterine rupture after previous caesarean section. Int $\mathbf{J}$ Obstetr Gynaecol. 2010;117(7):809-20.

Cite this article as: Sharma A, Singh D, Verma S, Sharma S. Fetal. Classification of caesarean section based on Robson ten group classification system in our hospital. Int J Reprod Contracept Obstet Gynecol 2020;9:4232-5. 